\title{
Relationship between Emotional Maturity and Personality traits among Adolescents
}

\author{
Swati Patrani ${ }^{1}$, Pranjali Bhakre ${ }^{2}$ \\ ${ }^{1}$ Assistant Professor \& Head, Department of Child Development, Maniben Nanavati Women's College, \\ Mumbai \\ ${ }^{2}$ Educational coordinator, Jeevandeep Edumedia Pvt. Ltd., Nagpur \\ Corresponding author: Swati Patrani \\ Email-swatip@gmail.com
}

\begin{abstract}
Background and Objectives: Adolescent is the most vital stage of development. Many physiological and psychological changes are taking place at this stage. Emotional and personality development play an important role in emotional independence and identity formation in adolescents. This study aims to find correlation between Emotional Maturity and Personality Traits among Adolescents.

Methods: Purposive sampling technique was used to collect sample of 300 students from 5 SSC board schools in western suburbs of Mumbai. Further, sixty students of $9^{\text {th }}$ grade were selected from each school. Sixteen Personality Factor Test (16 PF) was used to analyze Personality traits and Emotional Maturity Scale was used to measure Emotional Maturity among adolescents.

Results: Results revealed that, in terms of personality traits adolescent respondents were found to be warmhearted, affected by feelings, feel few obligations, conscientious, stubborn, socially bold, dependent, and suspicious. They were found to be practical, wrapped up in inner urgencies, experimenting, and selfconflicted, frustrated and group dependent. They were also found to be concrete thinkers, prudent, taciturn, and realistic.

Conclusion: On scale of emotional maturity most of adolescent respondents were found to be emotionally extremely unstable. There was positive correlation between total score for emotional maturity and personality traits dominance, privateness, warmth, sensitivity, abstractedness, and apprehension. Rest other traits reasoning, emotional stability, self-reliance and perfectionism, rule-consciousness, social boldness, vigilance, openness to change and tension had negative correlation with emotional maturity. These results can be recommended to schools to incorporate various programs to furnish adolescent's emotional and personality developmental needs.
\end{abstract}

Keywords: Emotional maturity, personality traits, adolescents.

(Paper received $-26^{\text {th }}$ June 2018, Peer review completed $-20^{\text {th }}$ August 2018)

(Accepted $-25^{\text {th }}$ September 2019)

\section{INTRODUCTION}

In the developmental stages of human being, adolescence is one of the very important stages where an individual is no longer a child but is in the process of becoming an adult. Adolescence is the period of development corresponds roughly to the period between the ages of 10 and 19 years, which is consistent with the World Health Organization's definition of adolescence. Yerpude mentioned that, In India, 21.4\% of total population belongs to age group of 10-19 years i.e. $1 / 5^{\text {th }}$ of total Indian population are adolescents [1]. Adolescence begins with the onset of physiologically normal puberty, and ends when an adult identity is formed. One of the major developmental tasks of adolescents consists of achieving emotional independence as well as forming an identity as an individual [2]. 
Adolescence is also known as the age of identity formation, where a person strives to establish his or her own identity in this society. Every person has some or the other characteristics which makes his or her personality. The combinations of attitudes, behaviour makes the personality of a person. Adolescent's personality traits have an impact of gender, genes, or even their environment. Larsen \& Buss (2005) defined personality as the set of psychological traits and mechanisms within the individual that are organized and relatively enduring and that influence his or her interactions with, and adaptations to, the intra psychic, physical, and social environments [3].

With regards to personality traits, the diagnostic and statistical Manual of Mental Disorder of the American Psychiatric Association posited that, personality traits are enduring patterns of perceiving, relating to and thinking about the environment and about oneself that are exhibited in a wide range of personal and social context [4]. Whereas other researchers maintained that a personality trait is a consistent and long lasting tendency in an individual's behaviour and action.

Arora quoted Stenberg said that "all people are essentially born with the same set of traits and that individual difference can be ascribed to the extent to which they are in possession [5]." Personality traits can differ among individuals depending on the situation or the degree to which person reflects a particular behaviour. One another most important perspective of development for an adolescent is their emotionality. Adolescents strive for attaining emotional maturity. At this stage of emotional development, adolescent's experiences much emotional turmoil sometimes adolescent become very happy or excited and at very next moment the same person will be sad about something. When an adolescent makes transition from childhood to adulthood, he or she strives to control their emotion, to become emotionally independent as it is one of the most important developmental tasks for them. An adolescent can only be called emotionally mature when he or she is able to regulate their emotion. And a person who is able to regulate emotions and express them in a controlled manner can be called as emotionally stable person.

It can be said that, emotional maturity among adolescent help them to make wiser choices which doesn't create harm. Singh defined 'Emotional maturity as not only the effective determinant of personality patterns but it also helps to control the growth of an adolescent's development. A person who is able to keep his emotions under control, which is able to rock delay and to suffer without self-pity, might still be emotionally stunted and childish [6].

As emotional maturity and personality traits are the most important components of adolescent's development, their interrelation was assessed by Kumar and others with the help of analysis of emotional maturity and personality factors [7]. The sample consists of 110 adolescents studying in class $11^{\text {th }}$ and $12^{\text {th }}$ taken from a private school. Further, the association of emotional maturity with personality dimensions of these adolescents was analysed. Emotional Maturity Scale was administered on the selected sample to assess emotional maturity and NEO-FFI (Form S), was used for measuring various personality dimensions of these adolescents. Result showed that neuroticism had a significant negative co-relation with emotional maturity, agreeableness and conscientiousness had significant positive co-relation with emotional maturity and traits openness and extraversion doesn't show any significant relation with emotional maturity.

\section{Rationale}

Personality of adolescent is developed with a combination of person's attitude, beliefs, emotions, behaviour etc. and a person's emotions are not just feelings but a unique way to express their thoughts, which differs from person to person so as personality. With the changing self and environment of adolescence, they start feeling uncomfortable, emotionally upset and tensed which further showcase their personality. Adolescents different reaction in different situations differs according to their personality, which also shapes their social identity, as adolescents are at the stage of identity formation. So, there is need to assess personality traits and emotional maturity among them. If adolescent's emotionality affects their behaviour which is an important constituent of their personality, there is a need to find relation between their personality traits and emotional maturity which can be helpful for them to control their reaction and to shape their personality. So, this study further tries to find correlation between two most important assets of development emotional maturity and personality traits. 


\section{Hypothesis}

\section{METHODOLOGY}

$\mathrm{H}_{01}$ : There is no statistical significant co-relation between personality traits and emotional maturity of adolescent.

\section{Research design}

Correlational design was used for this study.

\section{Sample}

Purposive sampling technique was used for sampling. Sample of 300 SSC board students were selected, from 5 schools in western suburb of Mumbai. From each school data of 60 students was collected. All these students belonged to $9^{\text {th }}$ grade, from which 150 were boys and rest 150 were girls.

\section{Tools}

Sixteen Personality Factor Test - R. B. Cattell [8]

Emotional Maturity Scale (1990) - Dr. Yashvir Singh and Dr. Mahesh Bhargava [9]

If the score for emotional maturity scale is more, the adolescent is emotionally extremely unstable i.e. as the score on emotional maturity scale increases, the emotional maturity decreases.

\section{Procedure for data collection}

From every permitted school, students were provided with information about purpose of study and consent was taken from them before administering this test on them. Sixty students from each school were provided with appropriate instructions for answering the tool and data was collected.

\section{STATISTICAL ANALYSIS}

The quantitative analysis was done for collected data with the help of Statistical software, in which test such as frequency, mean, and co-relation were used. The data representation was done through tables and graphs and results were discussed further.

\section{RESULTS AND DISCUSSION}

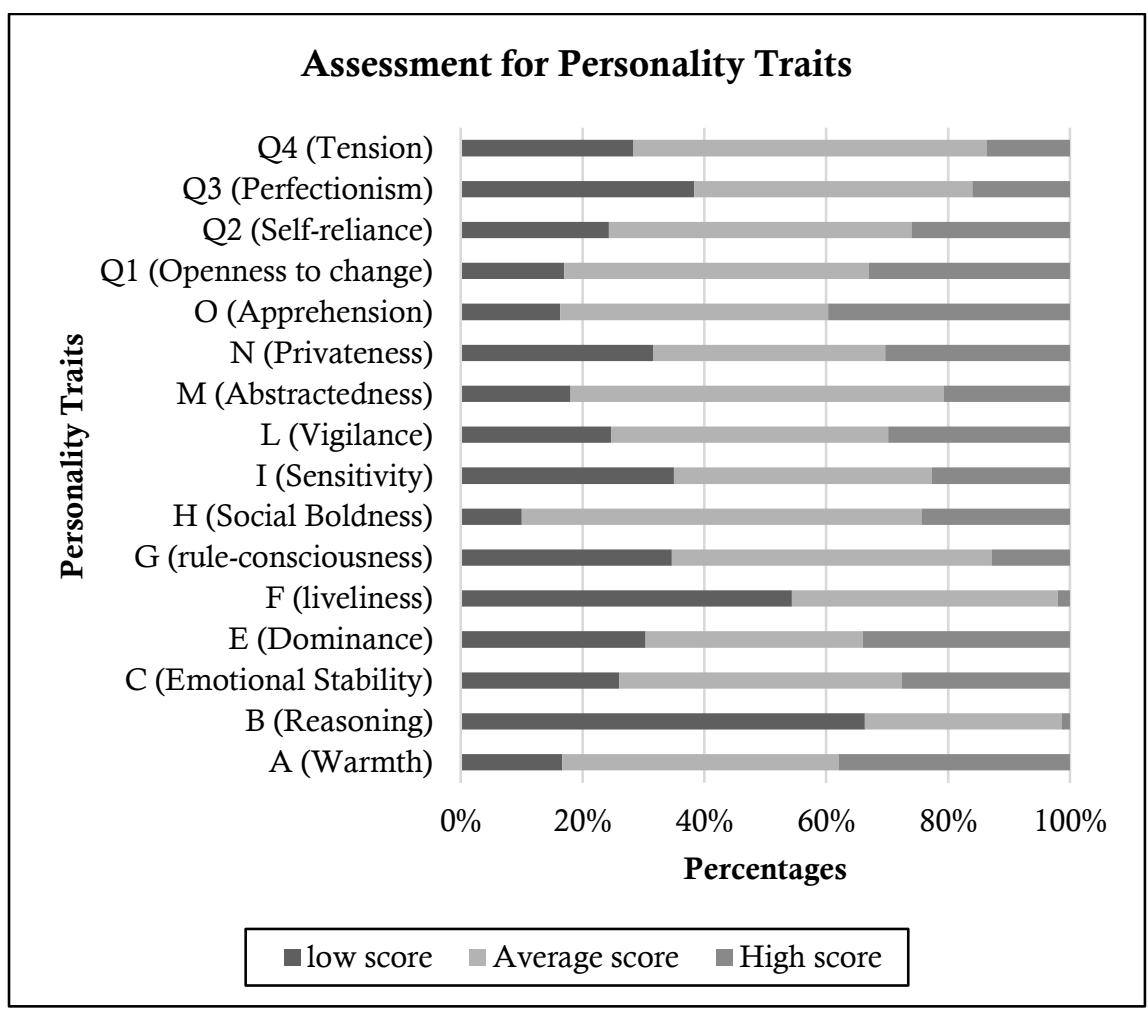

Figure 1.1 Percentages of Personality Traits among Adolescents 
According to the figure 1.1, traits apprehension (39.66\%), warmth (38\%), dominance (34\%) and openness to change (33\%) scored high as compared to other traits in adolescents. Social boldness $(65.66 \%)$, tension $(58 \%)$, rule-consciousness $(52 \%)$, self-reliance $(49.66 \%)$, emotional stability $(46.33 \%)$, sensitivity $(42.33 \%)$, vigilance (43.66\%), Abstractedness (45.33\%), perfectionism (45.66\%) and privateness $(38 \%)$, traits found to have average score for the adolescent respondents. Low scores were observed for reasoning $(66.33 \%)$ and liveliness (54.33\%) of the adolescent (1-4).

Adolescents were found to be warmer and easy going, as this stage, referred as age of rapid development. Developmental changes occur in the process of transition from childhood to adulthood, but still some traits of childhood like being sensitive and sympathetic can be usually seen in them. So, trait warmth in adolescents could be the result for these qualities among them. Trait of emotional stability in adolescents was scored less. They are emotionally volatile and not able to control their emotion at this age which makes them emotionally less stable. While for the trait of dominance, their emotional turmoil can sometimes make them aggressive and stubborn in some situations and they try to take control of the situation reflecting dominance. For trait openness to change adolescent respondents were critical, experimenting but less tolerant to traditional difficulties. Adolescents in this age are trying to know more about society but also being critical about some of the societal norms because it may cause hindrance in way to achieve independent identity, also they like to experiment with new things as they like to take risks and acceptable for the outcomes of those risks. Adolescents are generally reluctant for traditional thoughts, which hinder them in their decision making.

For the trait of social boldness adolescent were found to be venturesome, uninhibited and spontaneous which can be because adolescent like to involve more with peer, these group which is important socialization according to them, making them socially bold. Adolescents likely to involve more with peer groups than with their parents or other as it is a trait of this age and involve in risk taking behaviour. For trait of vigilance, adolescents were suspicious and self-opinionated, because of changes happening in their body adolescents often uncomfortable. When in this stage parent try to instruct them to act in certain way, it is hard for them behave according to them feeling obligation for rules and make them suspicious.

Abstractedness among adolescents revealed that adolescents were imaginative, wrapped up in inner urgencies, careless of practical matters. Adolescents are at most vulnerable stage of development; all the transitions happening at this stage can be reason for them to be wrapped up inner urgencies. Adolescents have characteristic of personal fable where they think that they are centre of attraction ignoring the practical aspect of day to day living. Adolescents are wrapped up with their own problems sometimes makes them careless of practical matters for which they are less concerned. For privacy, adolescent respondents were found to be shrewd, penetrating and sentimental because of traits they possess such as suspiciousness in them can make them shrewd, when they try to hide something. Sometimes their emotional state makes them sentimental and adolescents reacts differently to situation which is not deliberate but may hurt others unintentionally giving them trait of being penetrating.

For trait Apprehension, adolescent respondents were found to be more worrying, depressive and troubled. Adolescents wants to attain emotional, social independence and to form their own identity but all vulnerabilities and emotionality in them makes them worrying about future, depressed about their looks or appearance or sometimes troubled because of their risk-taking behaviour. Trait self-reliance among adolescents revealed them as they were group - dependent, prefered own decisions to become part of their fellow groups. Adolescents in this age like to be involved with their peers they prefer to have more friends making them more group dependent. While trying to become one of them adolescents like to takes their own decisions rather than other's taking decisions for them.

Perfectionism in adolescent respondents were showed that adolescents were self-conflicted, follows own urges, and careless of protocol. Adolescents trying to get independent to take their own decision but uncertainty in them lead to conflicts. Rules posed on them were obligations for them so they may act careless for protocols to be followed. For trait Tension, adolescents were found to be in average category. This suggested that adolescents were generally worried about their future, body image etc. But their experimental nature helps them to accept the changes or consequences happen because of risk taken. This acceptance can be reason for adolescent to have the trait of being unfrustrated. 
Rule-consciousness found to be in average category. An adolescent is in the process of transition from child to become an adult but during this process adolescent have to follow some of rules of being children. Many a times they follow rules to avoid the fear of being left out though ignorant many a times. Trait sensitivity among adolescent respondents was found to be tender-minded, dependent and sensitive. Adolescents might be affected easily by interaction with others. This also can be related with their tender mindedness and sensitivity for feeling of their own or even others and tends to give emotional reactions.

For the trait of reasoning adolescents were found to be concrete thinkers. According to developmental theories major brain development takes place till 5 years of age but even after that various part of brain such as pre frontal lobe or parietal lobes etc. are still developing in adolescence stage. According to cognitive development theory, adolescent able to reason from concrete things but abstract thinking is still developing in them across the maturity of their brain i.e. Adolescents can take decisions on concrete situation but hypodeductive thinking could be difficult for them. So, they could find it difficult to reason for abstract thoughts making them more concrete thinkers. Liveliness in adolescent respondents found to be less that they were sober, serious and taciturn, these adolescents are still developing their capacity for hypo-deductive reasoning and as they want to establish their identity as socially-precise personnel they tend to behave in socially acceptable way.

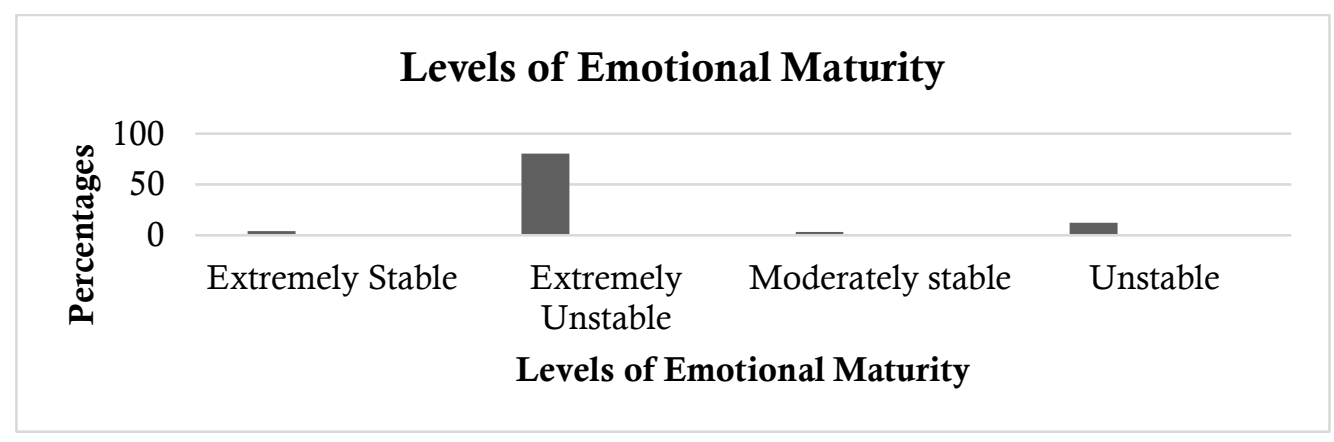

Figure 2.1 Percentage of Level of Emotional Maturity among Adolescents

The figure 1.2, illustrates the percentage of adolescents belong to different levels of emotional maturity. Only $4 \%$ of the samples were found to be extremely stable whereas $80.3 \%$ of samples were found to be extremely unstable. At this vulnerable stage of development, adolescents go through many changes which make them uncomfortable, and emotionally volatile. Adolescents are emotionally volatile. So, it can be seen that, they are overjoyed for something but can be sad at other moment. They can rarely take practical decisions and generally acts emotionally in most of situation which make them more emotionally unstable. These results can be supported with research done by Shafeeq and Thaqib on emotional maturity of secondary school students in relation to academic achievement found that most of secondary school students (i.e. $51 \%$ ) were extremely unstable, only (13.25\%) were extremely stable, (11\%) were moderately stable and remaining $(24.75 \%)$ were emotionally unstable [10].

As discussed in methodology, more the scores of emotional maturity, less is the emotional maturity. Results were interpreted accordingly. According to Table 3.1, for total score of emotional maturity, there was significant positive correlation with personality trait dominance $(\mathrm{r}=0.11, \mathrm{p}=0.05)$ and privateness $(\mathrm{r}=$ $0.16, p=0.00)$ and significant negative correlation with reasoning $(r=-0.11, p=0.05)$, emotional stability $(r=-0.16, p=0.01)$, self-reliance $(r=-0.11, p=0.05)$, and perfectionism $(r=-0.14, p=0.01)$. There was no significant correlation of emotional maturity with rest of the personality traits. When an adolescent is emotionally immature, they were found to be more dominant and more private as they can't understand how to react appropriate for situation and what they can share with another person be it a friend or family member etc. But emotional maturity score was negatively related with emotional stability because according to this study most adolescents were found to be emotionally unstable which can be reason for the negative correlation. Emotional maturity led them to reason more, make them self-reliant and perfectionist, because the mature person was found to be self-sufficient, able to take their own decisions and try to fulfil their 
responsibilities or develop those abilities for it. These adolescents were found to be warm hearted, practical and careful, self-assured and confident in their behaviour. This result can be supported by research done by Kumar, Sharma and Singh on Personality factors as correlates of Emotional Maturity among Adolescent which signifies that different traits have negative or positive correlation with emotional maturity. Traits such agreeableness and consciousness had significant positive correlation with emotional maturity. Neuroticism had negative correlation with emotional maturity.

Table 3.1, Co-relation between Personality Traits and Emotional Maturity

\begin{tabular}{|ll|}
\hline & Co-relation Value \\
& Emotional Maturity \\
\hline A (warmth) & 0.05 \\
\hline B (Reasoning) & $-0.11^{*}$ \\
\hline C (Emotional stability) & $-0.16^{* *}$ \\
\hline E (Dominance) & $0.11^{*}$ \\
\hline F (Liveliness) & 0.001 \\
\hline G (rule-consciousness) & -0.03 \\
\hline H(social boldness) & -0.19 \\
\hline I (Sensitivity) & 0.002 \\
\hline L (Vigilance) & -0.05 \\
\hline M (Abstractedness) & 0.04 \\
\hline N (Privateness) & $0.16^{* *}$ \\
\hline O (Apprehension) & 0.08 \\
\hline Q1 (Openness to change) & -0.07 \\
\hline Q2(Self-reliance) & $-0.11^{*}$ \\
\hline Q3 (Perfectionism) & $-0.14^{*}$ \\
\hline Q4 (Tension) & -0.03 \\
\hline$* *$ Correlation is significant at the 0.01 level * Correlation is significant at the 0.05 level
\end{tabular}

\section{CONCLUSIONS}

Adolescent respondents scored average on various personality traits, though scored more for traits warmth, dominance, and openness to change as compared to other personality traits. Whereas adolescents scored low for traits reasoning and liveliness.Most of the respondents were found to be emotionally extremely unstable. Reasoning, emotional stability, self-reliance and perfectionism increased with emotional maturity. Personality traits, dominance and privateness decreased with emotional maturity. This research can be done for other stages of adolescent to understand emotional maturity and personality traits among them. This research can be diversified by including other variables such as urban and rural, different age group etc. for better understanding of emotional and personality development among adolescents. Adolescents need to be educated for their better emotional development. It will also be helpful for their better personality development.

\section{REFERENCES}

1. Yerpude PN, Jogdand KS, Jogdand M. A study of health status among school going adolescents in South India. Int J Health Sci Res 2013;3(11):8-12.

2. Havighurst RJ. Education through the adult life span. Educ Gerontol 1976;1(1):41-51.

3. Larsen RJ, Buss DM. Personality psychology: domains of knowledge about human nature. Psicología de la personalidad: dominios de conocimiento sobre la naturaleza humana. 2005.

4. American Psychiatric Association. Diagnostic and statistical manual of mental disorders, American Psychiatric Association. Diagnostic and statistical manual of mental disorders $-4^{\text {th }}$ edition $; 2000$.

5. Singh Y, Bhargava M. Emotional maturity scale. Tehran: Allameh Tabatabaei University Publication. 1999:23-41.

6. Singh Y, Bhargava M. Manual for emotional maturity scale. Agra: National Psychological Corporation. 1990. 
7. Kumar S, Sharma M, Singh R. Personality Factors as Correlates of Emotional Maturity among Adolescents. J Indian Acad Appl Psychol 2014;40(2):221-6.

8. Conn SR, Rieke ML, editors. 16PF fifth edition technical manual. Institute for Personality \& Ability Testing, Incorporated; 1994.

9. Steinberg L, Cauffman E. Maturity of judgment in adolescence: Psychosocial factors in adolescent decision making. Law Hum Behav 1996;20(3):249-72.

10. Shafeeq NY, Thaqib A. Comparative study of emotional maturity of secondary school students in relation to academic achievement. Int J Soc Sci Hum Inv 2015;2(6):1437-44.

$* * * * * * * * * * * * * * * * * * * * * * * * * * * * * * * * * * * *$

Acknowledgements - Nil

Conflict of Interest - Nil

Funding - Nil 